\title{
A Taxonomy of Construction Material Reuse and Recycling: Designing for Future Disassembly
}

\author{
Philip Crowther ${ }^{1}$
}

\begin{abstract}
The construction and demolition industry accounts for approximately one third of all material waste in the industrialised nations of the world. This material and energy waste can however be reduced through increased levels of material and component reuse. A strategy of design for disassembly has been well implemented in product design and manufacture, but the construction industry has failed to adopt such approaches, largely due to the more bespoke nature of architectural projects. This paper explores the technological options for material and component disassembly in buildings. The research projects utilises inductive reasoning to conduct a number of architectural case studies, observing the reoccurring patterns of design that have facilitated material disassembly, then proposes a model or taxonomy of recycling and reuse strategies. The case studies reveal a hierarchy of recycling potentials, each facilitated by different strategies of design for disassembly. This hierarchical taxonomy of recycling can be used to guide design decisions at the early stages of architectural projects; thus increasing the potential for material and component recovery, and reduce negative environmental impact at the future stage of building obsolescence. The paper concludes with design principles, linked to the taxonomy of reuse and recycling.
\end{abstract}

\section{Introduction}

The construction of our built environment is a significant achievement in the industrialised nations of the world. It is also a significant problem due to the consumption of materials and energy to construct these achievements. 'Each year more than three billion metric tons of raw materials are used to manufacture construction materials and products worldwide. This is about $40-50 \%$ of the global economy's total flow' (Saghafi \& Teshnizi, 2011, p. 3).

Quantities and proportions of waste vary greatly between countries, however in the European Union, construction and demolition waste accounts for approximately $34 \%$ of total solid waste (Van Ewijk \& Stegemann, 2016). The USA generates 160 million tons of construction and demolition waste annually; representing approximately one third of the nation's total solid waste stream (Rios, Chong, \& Grau, 2015). Research in the USA shows that typical construction demolition waste is $40-50 \%$ concrete, $20-30 \%$ timber, with the remainder being primarily bricks, plaster wall sheeting, metals and plastics (Srour, Chong \& Zhang, 2012). The vast majority of this construction and demolition waste ultimately ends up in landfill, with just a small proportion being recycled.

There are some notable exceptions of high rates of material recycling from construction and demolition waste (CDW). 'In Europe, data on CDW management available from 18 EU member states shows that around $50 \%$ of $\mathrm{CDW}$ is recycled. However recycling is not homogenously practiced between member states' (Iacovidou \& Purnell, 2016, p. 
793). Research in the Netherlands has shown that $83 \%$ of steel building construction products are recycled, while only $14 \%$ are reused, with the remaining $3 \%$ going to landfill (Durmisevic \& Noort, 2003). Research in the USA, specifically targeted at increasing rates of material reuse and recycling, has shown that material and component recovery rates can be as high as $50 \%$ to $90 \%$, with many projects in the $80 \%$ range (Rios, Chong, \& Grau, 2015).

These large quantities and rates of material waste are also a problem of energy waste. 'In general, at least $70 \%$ of the environmental impact of an average construction material is attributed to the energy required for its production' (Iacovidou \& Purnell, 2016, p. 792); this is known as embodied energy. When materials are thrown away into landfill, this embodied energy is lost from the system. This level of energy loss is however more complicated when materials are recycled or component refurbished for reuse. These different levels of recycling each have different environmental impacts, some more or less detrimental than others.

There are clear issues in the industry with understanding the complexities of construction and demolition material reuse and recycling; what can be reused, what can be recycled, how, at what level, and how to facilitate future recycling. Iacovidou and Purnell (2016) note the need for a typology system that would assist designers and building contractors to account for the full range of reuse and recycling potentials of construction materials and components. While there are a range of hierarchical models for understanding material recycling options, they are generic and underdeveloped. 'The waste hierarchy in its current form an insufficient foundation for waste and resource policy to achieve absolute reductions in material throughput' (Van Ewijk \& Stegemann, 2016, p. 122).

The aim of the research presented in this paper is to develop a model that will assist designers and contractors to better understand the material recovery hierarchy, thereby increasing future rates of material and component recovery or reuse. This study proposes a decision support model, a taxonomy of construction material reuse and recycling, which can enable architects and designers to determine appropriate levels of reuse and recycling and achieve sustainable development in the built environment. Further to this the hierarchy is integrated with the principles of design for disassembly, such that buildings can be deconstructed in the future to achieve higher order reuse of components or whole buildings.

\section{Case Studies}

This research project has used an inductive approach to identify recurrent patterns of construction material and component recovery in the built environment. In particular, how have demolished or deconstructed buildings become a resources for new constructions or other applications beyond simply dumping them in landfill.

Two studies were conducted and the findings cross referenced to establish a hierarchical model of end of life scenarios of construction and demolition materials. The first study was of 77 buildings that had been deconstructed and their materials or components reused in the built environment. These case studies buildings were analysed for information on the hierarchical level of material or component recovery; how was 
material retrieved, and what was it reused for. The second study was of published research in the field of material and component recycling in both the built environment and in industrialised product manufacture. Again inductive reasoning was applied to uncover recurrent patterns of types of reuse and recycling.

There have always been cases of buildings that have been designed to be taken apart in the future to allow materials and components to be reused (Crowther, 1999a). Indeed some of the earliest human shelters were lightweight tents designed to be dismantled and relocated. The reuse of stone from dismantled buildings was common practice in ancient times, as was the design of timber buildings to facilitate the disassembly and reuse of components; common practice in Europe and Asia. More recently the development of cast iron and then steel has seen the development of building such as portable cottages for use in colonial settlements in the $18^{\text {th }}$ century, and the temporary Crystal Palace pavilion of the Great Exhibition of 1851 in London. The two world wars prompted technological development in temporary portable and buildings that could be easily disassembled. Most recently there has been some innovation in temporary buildings for expositions and Olympic Games where materials and components, and even whole buildings, have been designed to be recovered and reuses.

Results from analysis of the above cases reveals the following options (from most environmentally desirable to least desirable):

- Building relocation, either intact, or through disassembly and reassembly. Timber houses are regularly relocated as whole assemblies by truck. Many temporary exposition pavilions and Olympic Games buildings have been disassembled and relocated.

- Component reuse. Window assemblies, roof trusses, and whole prefabricated wall panels can be reused as is in new buildings.

- Component repair. Building services (HVAC, electrical, plumbing, etc.) can be serviced and renewed for use in new buildings.

- Material reuse. Simple elements of material such as steel beams can be reused. Bricks can be reused, as can sheet metal.

- Material remanufacture. Timber beams and posts can be re-milled or re-faced for use in new applications. Glass can be recut for new applications.

- Material recycling. Steel can be re-smelted to make new steel, as can many other metals. Concrete can be down-cycled to make aggregate or road base.

- Composting of materials. Organic materials may be returned to the natural environment for agricultural benefit.

- Incineration for recovery of embodied energy. Possible with materials such as timber and paper. It is also possible to extract new materials through incineration.

- Disposal, typically in landfill. Resulting in large quantities of waste and the loss of embodied energy.

\section{Recycling Hierarchy}

A formalised hierarchy of waste recovery has existed in Europe since at least 1979 (Van Ewijk \& Stegemann, 2016) but only in 2008 was such a prioritised hierarchy brought into legislation with the European Commission's Waste Framework Directive of 
2008, which proposes a four level hierarchy of; reuse, recycling, other recovery, and disposal. This model also proposes the higher level action of prevention, though this is strictly speaking not a waste management strategy, but an avoidance measure. This model has come under some criticism for lack of detail, and some researchers (Gharfalkar, et. al. 2015) have proposed extended models of this hierarchy to include replace, reduce, reuse, reprocess, recover (for energy), and return (to the natural environment as landfill).

The development of a hierarchy of recycling options is more common in industrialised product design and manufacture than in the construction industry. Scholarly analysis of these options goes back to at least the 1980s. The distinction of recycling as separate distinguishable options was addressed by Ayres (1996, p. 13-15) within a general discussion of 'ecological strategies' in industrial design and manufacturing. As well as recycling, he identifies the levels of reuse, repair, and remanufacture. Ayres (1996, p. 14) notes that the scenarios of 'reuse, repair, and remanufacture avoid many of the problems of recycling'; such as waste production and pollution directly resulting from recycling. Also writing on the topic of industrial ecology, Graedel (1995, p. 260-75) proposes the end of life scenarios of maintenance, recycle subassemblies, recycle components, and recycle materials. The recycling of components and subassemblies might alternatively be called remanufacturing since it involves the same process of disassembling components for use in new products. Graedel also recognises the environmental hierarchy of the scenarios, in which maintenance is environmentally preferable to remanufacturing which is in turn preferable to recycling.

Yet another group of end of life scenarios is proposed by Mabrab (1997, p. 152) who explicitly refers to the scenarios as a hierarchy. He uses the terms reuse, re-manufacture, recycle to high-grade materials, recycle to low-grade materials, incineration for energy content, and dump in landfill site. Here the scenario of maintenance is lost, but the scenario of recycle has been further broken down to high-grade and low-grade materials. A new scenario of incineration for energy content has also been added. Magrab notes that 'the higher one is in the... hierarchy the more the investment of raw materials, labor and energy is conserved'.

More recently Goggin and Browne (2000) have proposed a generic model for the hierarchy of recycling options. Their simple model has the levels of material reclamation, component reclamation, and remanufacturing. This model is a useful start, but does not provide significant guidance for building designers and contractors to determine future recycling potential in a building.

While the field of industrial design has addressed some of the issues of reuse and recycling through the theories of industrial ecology, the field of architecture and building design has not. Most writers in the field of environmentally sustainable architecture have noted the environmental advantages of reuse and recycling, and there are many excellent examples of built work where materials and components have been reused. Despite this, there is a general lack of critical analysis of the possible effects that reuse and recycling might have on the full life cycle of the built environment, and in particular a lack of debate on the implications of a hierarchy of end of life scenarios.

Researchers at Sheffield University (Fletcher, Popovic \& Plank 2000) are involved in the research of building design for future reuse and recycling. They build directly on the 
lessons of industrial ecology with the four end of life scenarios; reuse, repair, reconditioning, and recycling of materials. They then simplify the model by grouping the scenarios into two levels; the product level (reuse, repair, reconditioning), and the material level (recycling). Their model recognises a hierarchy in which some options are more environmentally preferable to others, such as product level reuse being a more efficient use of resources than material level recycling. While this research is important in relating a recycling hierarchy to waste from the built environment, it is not well resolved and the three levels are overly simplistic in comparison with proposals by other researchers in industrial design. There are for example, important differences between the reuse of a product and the reprocessing of a product, though this model does not accommodate them. This research has however suggested the need for further research into the hierarchy of recycling.

Guequierre and Kristinsson (1999), researching at the Delft University of Technology, have also identified a number of end of life scenarios for materials in the built environment. Their research is concerned with the analysis of existing buildings to determine the most appropriate end-of-life scenario for materials after demolition or deconstruction. Their concerns are not with how to achieve a higher end of life scenario through design, but with what can be done with existing building materials and components. For this reason their model also includes the non-reuse scenarios of landfill, and incineration. This results in a model with the four scenarios of; repair of products, recycling of materials, incineration, and landfill. Since the model has been devised as an assessment tool for existing buildings, there is no consideration of a scenario for whole building reuse as a system.

Similarly, Kibert, Chini and Languell (2000), at the University of Florida, have conducted much research into the disassembly or deconstruction of existing buildings for reuse and recycling. They propose an explicit waste management hierarchy that includes the levels of reduction, reuse, recycling, composting, burning, and landfill. In this hierarchy the level of recycling is further broken down in to down cycling, recycling and upcycling, in which each is slightly more environmentally advantageous that the previous. The level of reuse is similarly broken into the reuse of materials and the more advantageous reuse of components or products.

Gao, Ariyama, Ojima, and Meier (2001) propose a simple three level hierarchy based on the energy levels of recycling materials from demolished residential buildings. This simple model has the levels of; product recycling (reuse), material recycling (recycling for the same material use), and feedstock recycling (down cycling material to a different use). In an effort to promote closing the material resource loop in the construction industry, Sassi (2004) also proposes just three levels on a hierarchy; those of reuse, recycling, and down cycling. Despite extensive research into the design of buildings for future resource recovery, Thormark (2001) similarly proposes just three levels in a hierarchy; material and component reuse, material recycling, and incineration for energy recovery. Rios, Chong, and Grau (2015), also in research related to designing buildings for future resource recovery, propose just three levels of reduce, reuse, and recycle; though the activities of composting, incineration, and landfill are mentioned, they are not included in the hierarchy model.

Durmisevic and Brouwer (2002) have research the specifics of designing buildings for 
future material recovery and they propose four levels in a hierarchy of end of life cycle scenarios; reuse and remanufacture, recycling, incineration, and landfill. More recently research in Portugal (Couto \& Couto, 2010) has proposed a waste management hierarchy for construction and demolition waste based on the minimisation of resource consumption and environmental damage; these included six levels of reduce, reuse, recycle, compost, incinerate, and landfill.

\section{Developing a Taxonomy}

We can now combine the findings of the case studies with the analysis of existing hierarchies of waste recovery (Table 1) to develop a new model that is specific to the construction and demolition industry; a taxonomy of construction material recycling options. It is evident in the above analysis, even of research specifically in the construction and demolition industry, that there is great diversity in the hierarchical options being proposed, and that none represents all of the options available. A more fully developed taxonomy is needed to better inform designers, contractor, and building owners of the potential within the building for material and component recovery. 'The primary utility of typologies is in supporting problem-solving at a generic level through provision of generic models/types' (Goggin \& Browne, 2000, p. 189).

A new model can be proposed by replacing the once-through flow of materials extracted from the natural environment to disposal in landfill, with a range of alternative cycles, operating at different hierarchical levels. If buildings were designed to facilitate future disassembly, then the full range of end of life scenarios for materials and components could be realised. Such scenarios are illustrated in Figure 1, in which nine hierarchical levels of reuse and recycling are presented. This diagram represent a taxonomy of nine categories or levels in a hierarchy of construction material and component reuse and recycling.

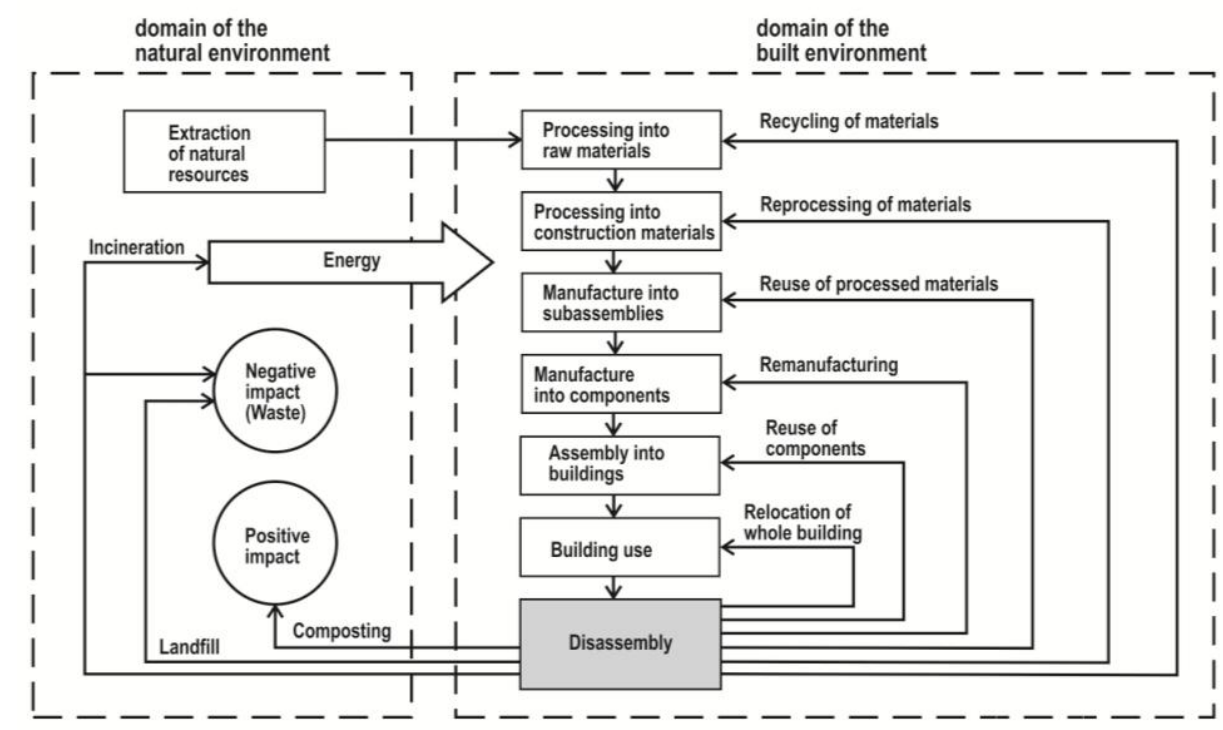

Figure1: Taxonomy of hierarchical levels of waste recovery scenarios 


\section{Conclusions}

The proposed model, or taxonomy, of reuse and recycling scenarios is intended to offer information and guidance to designers, contractors, and building owners on the future possibilities for the built environment. This model works for the analysis of existing buildings due for demolition or deconstruction, but it also provides guidance for the design of buildings to facilitate future disassembly in a way that can increase the material and component recovery potential of a building.

The major obstacles to reusing building materials and components are: social factors, environmental factors, economic factors, materials factors, stakeholders' factors, and regional factors. Srour, Chong and Zhang (2012) have shown that in most of these instances it is the designer who has the greatest control over possible changes that can improve future reuse and recycling. Couto and Couto (2010) have also shown that the designer has the greatest potential impact on the future levels of material and component reuse. The major factor preventing the higher order reuse of materials and components is that they have not been designed with future recovery in mind. The environmental benefits of designing for disassembly have been reported elsewhere (Crowther, 1999b) along with the specific design guidelines that can facilitate such future disassembly. These principles include the following:

- Use lightweight materials to facilitate easy handling of components.

- Size components to suit the proposed means of handling.

- Separate structure from cladding to allow changes to the building envelope.

- Provide access to all parts of the building that are to be disassembled.

- Arrange components in a hierarch of access related to life expectancy.

- Allow for parallel disassembly rather than just sequential disassembly.

- Use a modular system that is compatible with existing standards.

- Use low technology solutions and standard tools and practices.

- Minimise the number of different components and connectors.

- Use mechanical connections not chemical ones.

- Provide a means of identification of components and assembly instructions.

- Design using an open system that allows for structural alternatives.

- Avoid deformation of components due to repeated assembly process.

- Allow for disassembly at all scales from materials to whole buildings.

These principles have been adopted by a number of other researchers and authors as a foundation for further development of design for disassembly strategies to assist designers and contractors (Akinade, et. al., 2017). To date however, there has been no significant guidance on the application of the principles with a view to the final goal of reuse and recycling. The taxonomy presented here illustrates the hierarchy of environmentally preferred reuse and recycling options in the construction and demolition industry.

Such 'a taxonomy of resource recovery would provide a framework for solution development and decision support at a generic level' (Goggin \& Browne, 2000, p. 178). Taxonomies assist in: 'clarification and communication; revealing problem or critical 
areas that need attention; planning an organisation structure or system' (Goggin \& Browne, 2000, p. 178). Application of the design for disassembly guidelines can now be guided by this model of reuse and recycling in which decision making is better informed and conflicting guidelines can be assessed for their future environmental benefit.

Table1: Levels of waste recovery scenarios

\begin{tabular}{|c|c|c|c|c|c|c|c|}
\hline Reference & \multicolumn{3}{|c|}{ Least desirable 4} & End of Life Scenarios & \multicolumn{3}{|c|}{ Most desirable } \\
\hline Generic & prevent & reduce & reuse & & recycle & $\begin{array}{l}\text { recover } \\
\text { energy }\end{array}$ & disposal \\
\hline $\begin{array}{lr}\text { European } & \text { Waste } \\
\text { Framework } & \text { Directive } \\
(2008) & \\
\end{array}$ & prevent & & reuse & & recycle & $\begin{array}{l}\text { recover } \\
\text { energy }\end{array}$ & disposal \\
\hline Gharfalkar et. al. (2015) & replace & reduce & reuse & re-process & & recover & return \\
\hline $\begin{array}{|lcc|}\text { Van } \quad \text { Ewijk } & \& \\
\text { Stegemann (2016) } & \\
\end{array}$ & & & reuse & & recycle & $\begin{array}{l}\text { recover } \\
\text { energy }\end{array}$ & \\
\hline
\end{tabular}

\begin{tabular}{|c|c|c|c|c|c|c|}
\hline Ayres (1996) & reuse & repair & $\begin{array}{l}\text { remanu- } \\
\text { facture }\end{array}$ & recycle & & \\
\hline $\begin{array}{|lll|}\begin{array}{l}\text { Graedel } \\
(1995)\end{array} & \& & \text { Allenby } \\
\end{array}$ & & $\begin{array}{l}\text { repair } \\
\text { product }\end{array}$ & $\begin{array}{l}\text { remanu- } \\
\text { facture }\end{array}$ & recycle & & \\
\hline Magrab (1997) & reuse & & $\begin{array}{l}\text { remanu- } \\
\text { facture }\end{array}$ & recycle & $\begin{array}{l}\text { recover } \\
\text { energy }\end{array}$ & landfill \\
\hline $\begin{array}{l}\text { Goggin \& } \\
(2000)\end{array}$ & reuse & & $\begin{array}{l}\text { remanu- } \\
\text { facture }\end{array}$ & recycle & & \\
\hline
\end{tabular}

\begin{tabular}{|c|c|c|c|c|c|c|c|c|}
\hline $\begin{array}{l}\text { Fletcher, Popovic \& } \\
\text { Plank (2000) }\end{array}$ & $\begin{array}{l}\text { system } \\
\text { level }\end{array}$ & $\begin{array}{l}\text { product } \\
\text { level }\end{array}$ & $\begin{array}{l}\text { product } \\
\text { level }\end{array}$ & $\begin{array}{l}\text { product } \\
\text { level }\end{array}$ & $\begin{array}{l}\text { material } \\
\text { level }\end{array}$ & & & \\
\hline $\begin{array}{|ll|}\text { Guequirre } & \& \\
\text { Kristinnson (1999) } & \\
\end{array}$ & & $\begin{array}{l}\text { repair } \\
\text { product }\end{array}$ & \begin{tabular}{|l} 
repair \\
product
\end{tabular} & $\begin{array}{l}\text { repair } \\
\text { product }\end{array}$ & recycle & & $\begin{array}{l}\text { recover } \\
\text { energy }\end{array}$ & landfill \\
\hline Kibert \& Chini (2000) & & $\begin{array}{l}\text { reuse } \\
\text { product }\end{array}$ & $\begin{array}{l}\text { reuse } \\
\text { product }\end{array}$ & $\begin{array}{l}\text { reuse } \\
\text { material }\end{array}$ & recycle & compost & $\begin{array}{l}\text { recover } \\
\text { energy }\end{array}$ & landfill \\
\hline $\begin{array}{l}\begin{array}{l}\text { Durmisevic \& Brouwer } \\
(2002)\end{array} \\
\end{array}$ & & reuse & & $\begin{array}{l}\text { remanu- } \\
\text { facture }\end{array}$ & recycle & & $\begin{array}{l}\text { recover } \\
\text { energy }\end{array}$ & landfill \\
\hline Couto \& Couto (2010) & & reuse & & & recycle & compost & $\begin{array}{l}\text { recover } \\
\text { energy }\end{array}$ & landfill \\
\hline Gao et. al. (2001) & & $\begin{array}{l}\text { product } \\
\text { recycle }\end{array}$ & & $\begin{array}{l}\text { material } \\
\text { recycle }\end{array}$ & $\begin{array}{l}\text { feedstock } \\
\text { recycle }\end{array}$ & & & \\
\hline Thormark (2001) & & reuse & & & \begin{tabular}{|l} 
recycle \\
material
\end{tabular} & & $\begin{array}{l}\text { recover } \\
\text { energy }\end{array}$ & \\
\hline $\begin{array}{l}\text { Rios, Chong \& Grau } \\
(2015)\end{array}$ & reduce & reuse & & & recycle & & & \\
\hline Sassi (2004) & & reuse & & $\begin{array}{l}\text { material } \\
\text { recycle }\end{array}$ & down cycle & & & \\
\hline
\end{tabular}

\section{References}

Akinade, O. O., Oyedele, L. O., Ajayi, S. O., Bilal, M., Alaka, H. A., Owolabi, H. A., ... \& Kadiri, K. O. (2017). Design for Deconstruction (DfD): Critical success factors for diverting end-of-life waste from landfills. Waste management, 60, 3-13.

Ayres, R. U., \& Ayres, L. W. (1996). Industrial Ecology - Towards Closing the Materials Cycle. Cheltenham: Edward Elgar Press.

Couto, A., \& Couto, J. P. (2010). Guidelines to improve construction and demolition waste management in Portugal. In Process Management. InTech.

Crowther, P. (1999a). Historic Trends in Building Disassembly. In Tecbnology in Transition: Mastering the Impacts ACS A/CIB 1999 International Science and Technology Conference, (pp. 33-36), Montreal, Canada: ACSA Press. 
Crowther, P. (1999b). Design for Disassembly to Extend Service Life and Increase Sustainability. In Lacasse, Michael A. \& Vanier, Dana J. (Eds.) Durability of Building Materials and Components 8: Service Life and Asset Management, (pp. 1983-1992), Vancouver, Canada: NRC Research Press.

Crowther, P. (2009). Designing for Disassembly. Newton, P., Hampson, K., \& Drogemuller, R. (Eds.) Technology, Design and Process Innovation in the Built Environment, (pp. 224-237), London: Spon Press.

Durmisevic, E., \& Brouwer, J. (2002). Design aspects of decomposable building structures. Delft University of Technology. Department of Building Technology. Proceedings of the CIB Task Group.

Durmisevic, E., \& Noort, N. (2003). Re-use potential of steel in building construction. In CIB Publication (Vol. 287).

Fletcher, S. L., Popovic, O., \& Plank, R. (2000). Designing for future reuse and recycling. DeconstructionClosing the Loop, Watford, Building Research Establishment (BRE). CIB.

Gharfalkar, M., Court, R., Campbell, C., Ali, Z., \& Hillier, G. (2015). Analysis of waste hierarchy in the European waste directive 2008/98/EC. Waste management, 39, 305-313.

Goggin, K., \& Browne, J. (2000). Towards a taxonomy of resource recovery from end-of-life products. Computers in Industry, 42(2-3), 177-191.

Graedel, T. E., \& Allenby, B. R. (1995). Industrial Ecology. New Jersey: Prentice Hall.

Guequierre, N. M. J., \& Kristinsson, J. (1999, May). Product features that influence the end of a building. In Lacasse, Michael A. \& Vanier, Dana J. (Eds.) Durability of Building Materials and Components 8: Service Life and Asset Management, (2021-2032), Vancouver, Canada: NRC Research Press.

Iacovidou, E., \& Purnell, P. (2016). Mining the physical infrastructure: Opportunities, barriers and interventions in promoting structural components reuse. Science of the Total Environment, 557, 791807.

Kibert, C. J., \& Chini, A. R. (2000). Overview of Deconstruction in Selected Countries. In CIB Publication (Vol. 252). University of Florida.

Magrab, E. B., Gupta, S. K., McCluskey, F. P., \& Sandborn, P. (2009). Integrated product and process design and development: the product realization process. Boca Raton: CRC Press.

Rios, F. C., Chong, W. K., \& Grau, D. (2015). Design for disassembly and deconstruction-challenges and opportunities. Procedia engineering, 118, 1296-1304.

Saghafi, M. D., \& Teshnizi, Z. S. H. (2011). Recycling value of building materials in building assessment systems. Energy and Buildings, 43(11), 3181-3188.

Sassi, P. (2004). Designing buildings to close the material resource loop. In Proceedings of the Institution of Civil Engineers-Engineering Sustainability (Vol. 157, No. 3, pp. 163-171). Thomas Telford Ltd.

Srour, I., Chong, W. K., \& Zhang, F. (2012). Sustainable recycling approach: an understanding of designers' and contractors' recycling responsibilities throughout the life cycle of buildings in two US cities. Sustainable Development, 20(5), 350-360.

Van Ewijk, S., \& Stegemann, J. A. (2016). Limitations of the waste hierarchy for achieving absolute reductions in material throughput. Journal of Cleaner Production, 132, 122-128. 